\title{
O ESTÁGIO NA LICENCIATURA EM GEOGRAFIA COMO UM ESPAÇO DE FORMAÇÃO COMPARTILHADA
}

\author{
THE SHARED EDUCATION ENVIRONMENT OF THE PRACTICUM WITHIN \\ THE TEACHING PROGRAM IN GEOGRAPHY
}

\author{
PRÁCTICA EN LICENCIATURA EN GEOGRAFÍA COMO UN ESPACIO \\ DE FORMACIÓN COMPARTIDA
}

\author{
Rosa Elisabete Militz Wypyczynski Martins - Universidade do Estado de Santa Catarina - \\ Florianópolis - Santa Catarina - Brasil \\ rosa.martins@udesc.br
}

\begin{abstract}
Resumo
Através deste artigo, apresentam-se resultados de uma pesquisa que faz parte de um movimento de investigação dos estudos que têm sido desenvolvidos com o projeto de pesquisa "O Papel do Estágio Supervisionado no Contexto da Formação do Professor de Geografia", inserido na linha de pesquisa Ensino de Geografia e Formação Docente, no grupo de pesquisa "Ensino de Geografia, formação docente e diferentes linguagens", institucionalizado na Universidade Estadual de Santa Catarina (UDESC), junto ao curso de graduação em Geografia licenciatura no Departamento de Geografia da UDESC e no curso de Pós-Graduação em Geografia da Universidade Federal de Santa Catarina (UFSC), nos quais a preocupação em investigar o processo de formação do professor e o ensino de Geografia tem sido o foco. Nosso objetivo neste artigo é compreender qual é o papel do professor regente da escola básica na formação dos estagiários e futuros docentes, através do acompanhamento do estágio de docência nas suas turmas, de alunos do curso de Geografia da Universidade do Estado de Santa Catarina - UDESC/FAED.

Palavras-chave: estágio, ensino de Geografia, professor regente, educação básica.
\end{abstract}

\begin{abstract}
Through this article, we intend to present results of a survey that is part of a movement of research studies that have been developed within the research project "The Role of Practicum in the Context of Geography Teacher Education", inserted in the research line of Geography Teaching and Teacher Education by the research group called "Geography Teaching, Teacher Education, and Different Languages" institutionalized at Universidade Estadual de Santa Catarina (UDESC), as part of its undergraduate teaching program in Geography in collaboration with the Graduate Program in Geography at Universidade Federal de Santa Catarina (UFSC). Our concern lies in investigating the process of teacher education, with focus on Geography teaching. The objective of this article is to understand the role of the classroom teacher in basic education when advising Practicum students and future Geography teachers studying at UDESC.

Key words: practicum, Geography teaching, classroom teachers, basic education.
\end{abstract}

\section{Resumen}

A través de este artículo, se presentan resultados de una investigación que hace parte de un movimiento de pesquisa de los estudios que han sido desarrollados en el proyecto de investigación "El Papel de la Práctica Supervisada en el Contexto de la Formación del Profesor de Geografía", inserido en la línea de investigación Enseñanza de Geografía y Formación Docente, en el grupo de investigación "Enseñanza de Geografía, formación docente y diferentes lenguajes" institucionalizado en la Universidad Estadual de Santa Catarina (UDESC), junto al curso de graduación en Geografía licenciatura del Departamento de Geografía de la UDESC y en el curso de Post-Grado en Geografía de la Universidade Federal de Santa Catarina (UFSC), en los cuales, el foco ha sido la 
preocupación de investigar el proceso de formación del profesor y la enseñanza de Geografía. Nuestro objetivo en este artículo es comprender cuál es el papel del profesor regente de la escuela básica en la formación de los practicantes y futuros docentes a través del acompañamiento de la práctica de la docencia en sus clases, de alumnos del curso de Geografía de la Universidad del Estado de Santa Catarina - UDESC/FAED.

Palabras clave: práctica, enseñanza de Geografía, profesor regente, educación básica.

Introdução

O estudo apresentado neste artigo é parte dos resultados de uma pesquisa que está sendo desenvolvida com o projeto de pesquisa “ $\mathrm{O} \mathrm{Pa}$ pel do Estágio Supervisionado no Contexto da Formação do Professor de Geografia”, no curso de Geografia da Universidade do estado de Santa Catarina (UDESC), tendo como objetivo compreender qual é o papel do professor regente da escola básica na formação dos estagiários e futuros docentes, através do acompanhamento do estágio de docência nas suas turmas, de alunos do curso de Geografia da UDESC/FAED. ${ }^{1}$ O recorte dado ao estudo deriva de interesse pessoal e profissional, em olhar com mais profundidade e atenção o trabalho realizado pelo professor de Geografia regente de turma da escola durante as atividades de estágio.

Temos interesse em investigar as aprendizagens desenvolvidas pelos alunos da licenciatura em Geografia durante o período do estágio, a partir de um olhar sobre a importância que o professor regente detém neste processo. Acreditamos que o professor regente da educação básica também atua como formador de professores, transmitindo seus saberes profissionais, constituídos ao longo da sua experiência em sala de aula.

Para tratar desta discussão, primeiramente, apresentam-se os aspectos legais que norteiam o Estágio Curricular Supervisionado no que diz respeito às Diretrizes e Resoluções, concepção de prática e aos conceitos teóricos utilizados após a implantação da LDB 9394/96. Em seguida, expomos os relatos de um estudo que faz parte de um projeto de pesquisa "O Papel do Estágio Supervisionado no Contexto da Formação do Professor de Geografia", realizado em 2013, em quatro escolas públicas da Grande Florianópolis (SC).

Consideramos que o estágio supervisionado possibilita ao futuro professor o desenvolvimento e a prática dos conhecimentos teóricos adquiridos no decorrer da sua licenciatura, vivenciados durante a regência de classe e a realidade da sala de aula, resultando na produção de conhecimentos fundamentais na construção da profissão de professor. Entendemos que se constituir professor é um processo longo e complexo 
que é consolidado, gradativamente, nas vivências do curso de formação inicial e nas diversas experiências que vão sendo construídas, através da socialização de conhecimentos e da mobilização dos diversos saberes da profissão docente. O processo de formação inicial do professor não acontece somente com o estágio supervisionado, mas é nele que se concretiza a experiência da condição de ser professor. De acordo com Pimenta e Lima (2004), o Estágio Curricular Supervisionado é um campo de conhecimento que permite a interação dos cursos de formação inicial com os espaços da escola onde acontecerão as práticas educativas.

No espaço da escola, temos o professor regente da Educação Básica que detém papel fundamental na formação inicial de alunos estagiários. Ele desempenha função relevante junto aos alunos estagiários, pois ao ceder seu espaço de sala de aula favorece o contato com esta realidade que é fundamental à aprendizagem dos licenciandos; além de fazer um acompanhamento direto em todas as atividades realizadas neste espaço com as crianças e adolescentes, alunos que fazem parte da sala de aula. Por isso, julgamos muito importante realizar esta pesquisa, destacando a voz destes professores que são parceiros na formação dos alunos oriundos das licenciaturas.

\section{0 estágio na formação docente}

O Estágio supervisionado é uma exigência da Lei de Diretrizes e Bases da Educação Nacional (LDB) n. 9394/96 nos cursos de formação de docentes, propiciando ao aluno a obtenção da experiência profissional que é importante para a sua formação e experiência com a profissão. É uma atividade obrigatória que deve ser realizada pelos alunos de cursos de Licenciatura, devendo ser cumprida uma carga horária que é estabelecida por legislação específica. A articulação entre teoria e prática é um dos fundamentos legais à formação dos profissionais da educação, e o estágio de docência visa à inserção destes profissionais no contexto de espaços educativos, a fim de que possam vivenciar a organização e o desenvolvimento do trabalho pedagógico presente no cotidiano da escola.

Na tentativa de implantar novas ações na formação de professores para a Educação Básica em âmbito superior, com qualidade e competência, foram criadas as Diretrizes Curriculares Nacionais. Visando à superação dos modelos desarticulados na formação docente, no Parecer CNE/ 
CP 9/2001 é encontrada uma Proposta de Diretrizes à Formação de Professores da Educação Básica em cursos na esfera superior para licenciaturas de graduação plena. A prática, com essa normatização, deveria ocorrer ao longo do curso de formação, desde o primeiro ano como uma ação integrada e não apenas no Estágio Supervisionado. O referido parecer dispõe sobre nova concepção de prática, como uma dimensão de conhecimento que está presente nos diversos momentos durante o processo de formação, apoiada em reflexões críticas sobre a atividade profissional. "A ideia a ser superada é a de que o estágio é o único espaço reservado à prática, enquanto, na sala de aula se dá conta da teoria" (Brasil, Parecer CNE/CP 9/2001, p. 23).

Em 2002, foi aprovada a Resolução CNE/CP n. 1/2002, fundamentada nos Pareceres CNE/CP 9/2001 e 27/2001, estabelecendo as Diretrizes Curriculares Nacionais para a Formação de Professores da Educação Básica em âmbito superior, curso de licenciatura, de graduação plena. Esta Resolução se tornou reguladora dos procedimentos concernentes à reforma e à organização curricular dos cursos de formação inicial de professores para atuação na educação básica. Com a aprovação das DCNS, os currículos dos cursos de formação inicial de professores foram repensados e redesenhados, implementando não somente a ampliação de carga horária, no que diz respeito às práticas pedagógicas, mas também no sentido atribuído às relações dialógicas entre teoria e prática e a articulação entre pesquisa e ensino. Em lugar de conteúdos e disciplinas fica determinado pela Resolução CNE/CP n. 1/2002, competências e âmbitos de conhecimentos, os quais manifestam o que será considerado relevante na profissionalização dos educadores (Brasil, 2002).

O objetivo principal exposto no Parecer CNE/CP 9/2001 é o de estabelecer novos parâmetros à formação de professores no Brasil e garantir para as licenciaturas nova legislação, que lhes dê "terminalidade e integralidade própria em relação ao Bacharelado, constituindo-se em um projeto específico". Com isso, a Licenciatura ganha identidade própria para dar conta de uma preparação com qualidade ao profissional da educação. No Artigo $7^{\circ}$ do Projeto de Resolução anexado ao Parecer CNE/CP 09/2001 é ressaltado que, "a serviço do desenvolvimento de competências a formação deverá ser realizada em processo autônomo, em curso de licenciatura, numa estrutura com identidade própria”.

Em outubro de 2001, foi aprovado o Parecer CNE/CP n. 28/2001, que deu nova redação ao Parecer CNE/CP n. 21/2001, estabelecendo a du- 
ração e a carga horária dos cursos de Formação de Professores da Educação Básica em nível superior, curso de licenciatura, de graduação plena. Este Parecer compreende o Estágio Curricular Supervisionado de ensino como "tempo de aprendizagem que, através de um período de permanência, alguém se demora em algum lugar ou ofício para aprender a prática do mesmo e depois poder exercer uma profissão ou ofício", o qual "supõe uma relação pedagógica entre alguém que já é um profissional reconhecido em um ambiente institucional de trabalho e um aluno estagiário. Por isso é que este momento se chama Estágio Curricular Supervisionado”.

Nas Diretrizes, a concepção de formação de professores diante da prática não aparece restrita ao Estágio, mas presente desde o início do curso. O Estágio Curricular Supervisionado passa a ser considerado espaço interdisciplinar de formação, com o objetivo de proporcionar maior conhecimento da realidade profissional, através de um processo de estudo, análise, problematização e reflexão sobre a realidade de atuação docente. É um momento favorável à ação-reflexão-ação do exercício profissional, constituindo-se em espaço privilegiado de formação.

Visando regulamentar a duração e a carga horária dos cursos de licenciatura, é aprovada, em 19 de fevereiro de 2002, a Resolução CNE/ CP 02, fundamentada no Art. 12 da Resolução CNE/CP 1/2002 e no Parecer CNE/CP 28/2001, estipulando 400 horas à prática como componente curricular, vivenciada ao longo do curso e 400 horas de estágio curricular supervisionado, a partir do início da segunda metade do curso. Esta resolução regulamenta a carga horária dos cursos de formação de professores, expressando a ênfase na dimensão prática:

Art. $1^{\circ}$ A carga horária dos cursos de Formação de Professores da Educação Básica, no âmbito superior, em curso de licenciatura de graduação plena será efetivada mediante a integralização de, no mínimo, 2800 (duas mil e oitocentas) horas, nas quais a articulação teoria-prática garanta, nos termos dos seus projetos pedagógicos, as seguintes dimensões dos componentes comuns:

I - 400 (quatrocentas) horas de prática como componente curricular, vivenciadas ao longo do curso;

II - 400 (quatrocentas) horas de estágio curricular supervisionado a partir do início da segunda metade do curso;

III - 1800 (mil e oitocentas) horas de aulas para os conteúdos curriculares de natureza científico-culturais;

IV - 200 (duzentas) horas para outras formas de atividades acadêmico-científico-culturais. Parágrafo único. Os alunos que exerçam 
atividade docente regular na educação básica poderão ter redução da carga horária do estágio curricular supervisionado até o máximo de 200 (duzentas) horas. (Brasil, Resolução 02/2002)

No Parecer CNE/CP 28/2001, consta a prática como componente curricular, ressaltando que deve ocorrer relação constante entre teoria e prática, propiciando uma discussão contínua entre o saber e o fazer. É destacado, no documento, que a prática como componente curricular se distingue da prática de ensino, considerando-a como um componente mais abrangente, que se estende ao longo do curso.

As Diretrizes Curriculares Nacionais para a Formação de Professores da Educação Básica em Âmbito Superior (DCNs), decorrentes de políticas propostas para a educação no Brasil, trouxeram novos elementos ao debate sobre a formação inicial de professores, determinando princípios e propondo mudanças estruturais importantes. Apesar de todas estas mudanças previstas, há muita resistência das áreas específicas em relação à carga horária destinada às Práticas Pedagógicas como Componentes Curriculares e aos Estágios Curriculares Supervisionados. Os professores que trabalham nas áreas específicas da Geografia criticam o grande número de horas destinadas a atividades vinculadas à prática docente, alegando que um professor tem de ter conhecimento na sua área específica de formação. Um dos grandes desafios dos cursos de formação de professores de Geografia é o de fazer a articulação dos conteúdos específicos da ciência geográfica com os componentes curriculares pedagógicos e educacionais. A formação de professores de qualquer área precisa considerar a questão pedagógica, pois além dos conhecimentos específicos é fundamental ter os conhecimentos didáticos pedagógicos. (Martins, 2010).

O curso de Geografia Licenciatura e bacharelado da UDESC/FAED, no qual os alunos em estágio estão matriculados, tem uma matriz curricular que foi implantada em 2008, oferecendo as duas habilitações. ${ }^{2} \mathrm{O}$ curso apresenta como característica principal a pluralidade de ideias e o aprimoramento da ciência geográfica. Esta concepção de formação visa contribuir de forma crítica e criativa para a solução de problemas nas escalas local, regional, nacional e mundial, alicerçadas na perspectiva de relação entre Sociedade e Natureza. A matriz curricular proposta está de acordo com a Resolução CP/CNE 02/2002 de 19/02/02, que definiu critérios e fixou a carga horária dos cursos de Formação de Professores da Educação Básica em, no mínimo, 2.800 (duas mil e oitocentas horas), sendo 400 
horas de Estágio Curricular Supervisionado, 400 horas de prática como componente curricular, e 200 horas de atividades acadêmicas de caráter científico-culturais, exigindo um redimensionamento das disciplinas e de suas respectivas cargas horárias, de modo a atender tais determinações. O curso de Geografia tem como objetivo geral a formação do bacharel, assim como do professor/ educador/ profissional do ensino da Geografia.

Quando se discute a formação acadêmica, a temática sobre Estágio Curricular Supervisionado aparece com grande destaque. É um componente curricular obrigatório que oportuniza, ao estudante, o desenvolvimento de aprendizagens significativas para ampliar as competências e habilidades indispensáveis à formação dos licenciados e sua relação com a profissão e à profissionalidade docente. É um lócus da formação profissional que se efetiva na parceria entre universidade e escola. É preciso reconhecer que a escola é um espaço real de formação profissional, em especial pela sua participação efetiva nos estágios, onde os alunos vivenciam a iniciação na docência. O papel do professor regente é fundamental no acompanhamento do estagiário, trocando experiências, discutindo tarefas, auxiliando na proposição de metodologias, aprofundando reflexões, estabelecendo um olhar crítico sobre as atitudes do aluno estagiário no cotidiano da sala de aula.

É necessário que exista um ambiente favorável para que o estágio, de fato, seja uma experiência significativa na vida do futuro professor com um projeto de parceria e colaboração entre a universidade e a escola que ajuda romper barreiras entre o conhecimento teórico e prático. Esta postura possibilita que o estágio seja um espaço de formação onde as tarefas são compartilhadas no sentido de efetivamente dar a sustentação aos estagiários nesses primeiros passos rumo a sua preparação profissional.

A pesquisa que será relatada é uma maneira de destacar o papel da escola e dos professores regentes que recebem os estagiários na formação destes futuros profissionais. Pretende-se, neste artigo, dar destaque às contribuições destes profissionais na construção da profissionalidade dos alunos da licenciatura na aquisição dos saberes fundamentais da docência.

No contexto de formação investigado por esta pesquisa, será dada voz aos professores regentes de turma da escola como um modo fecundo de compartilhar os significados que produzem a respeito dos saberes ligados à experiência docente e os aspectos da aprendizagem da docência por meio dos estágios. Nesse sentido, a pesquisa é composta pelos relatos 
produzidos por estes professores que compartilham com os professores supervisores da universidade a formação dos estagiários. Durante o período de coleta de dados, cada professor procurou relatar todo o processo reflexivo de problematização e constituição dos saberes construídos ao longo do período do estágio de docência em Geografia em que os estagiários estiveram em suas turmas na escola.

\section{Caminhos da pesquisa}

Trabalhamos no departamento de Geografia da FAED com a supervisão de estágios e projetos na área do ensino de geografia e formação docente. A presente pesquisa, que faz parte de um projeto de pesquisa "O Papel do Estágio Supervisionado no Contexto da Formação do Professor de Geografia”, foi realizado no ano de 2013 em quatro escolas públicas de educação básica de dois municípios do Estado de Santa Catarina; duas em Florianópolis e duas em São José, que chamaremos de: escolas 01 e 02 as de São José; 03 e 04 as de Florianópolis. Todas as escolas são públicas e atendem alunos do ensino fundamental e médio. Optamos por não identificar as escolas, com o intuito de preservar os professores regentes e os alunos estagiários envolvidos na pesquisa.

Os sujeitos que participaram da pesquisa foram sete professores de Geografia, regentes das turmas das escolas citadas. Nas escolas 01 e 02 temos dois professores de Geografia em cada uma delas, tendo formação em Geografia Licenciatura e atendem alunos do ensino fundamental do $6^{\circ}$ ao $9^{\circ}$ ano. Serão chamados, ao longo do texto, de PA da escola 01 e PB da escola 01; PA da escola 02 e PB da escola 02. São professores efetivos com mais de cindo anos de magistério e sempre recebem estagiários em suas turmas.

Nas escolas 03 e 04 temos três professores, sendo dois na escola 03, e 01 na escola 04, que serão chamados, ao longo do texto, de PA da escola 03, PB da escola 03 e PA da escola 04. Todos têm graduação em Geografia, sendo que um possui Mestrado em Geografia. São profissionais com mais de cinco anos de magistério, sendo que um deles conta 25 anos de trabalho. Estes professores receberam em suas turmas dez alunos/as estagiários/as no ano de 2013 para estágio no ensino médio.

A matriz curricular do curso de Geografia da FAED que está em extinção exibe, em sua proposta, a previsão de quatro estágios curriculares supervisionados. Denominados de Estágios Curriculares Supervisionados 
- Prática de Ensino em Geografia I, II, III e IV. O estágio I e o II são destinados ao ensino de Geografia no ensino fundamental, e os estágios III e IV ao ensino de Geografia no ensino médio.

Entende-se, através das entrevistas abertas realizadas e dos relatos orais, qual o espaço ocupado pelo professor regente da escola pública na formação inicial dos futuros professores de Geografia, além de investigar se eles se percebem como formadores ou coformadores de outros professores. A pesquisa foi organizada com duas questões centrais que foram direcionadas na tentativa de entender o papel dos estágios na aprendizagem e formação dos futuros professores; e qual a importância do professor regente da educação básica no processo de constituição da docência dos estagiários de Geografia.

Com alguns professores regentes, principalmente aqueles das escolas 01 e 02 que não tinham estagiários/as de Geografia da FAED,3 priorizou-se uma conversa mais formal, com horário marcado para tratar das questões da pesquisa. Com os demais professores, optou-se por não fazer uma pesquisa formal com horário marcado, mas sim aproveitar o tempo destinado ao estágio na escola, a fim de fazer supervisão, semanalmente, para então falar sobre as duas questões da pesquisa. Durante a realização do estágio, estávamos na escola toda semana para fazer o acompanhamento direto e sistemático. Com os professores regentes das turmas dos estagiários, fez-se reunião a cada quinze dias pelo menos, para saber qual era o parecer deles sobre o andamento das atividades dos estagiários/as. Nestes momentos conversávamos sobre as questões da pesquisa. A modalidade de entrevista utilizada foi a do tipo aberta, na qual o informante pode discorrer livremente sobre o assunto em pauta, com um roteiro mínimo, podendo sua fala discorrer a partir das suas experiências pessoais, acerca da temática proposta para a conversa.

O estágio supervisionado é um espaço de formação e construção de saberes que tem como foco principal a condução dos alunos na tarefa de assumir uma sala de aula. Entendemos que é uma oportunidade ímpar de experimentar e vivenciar a construção do saber ser e do saber fazer da profissão, através da vivência, da experiência, da reflexão e da própria prática da docência.

Passaremos a relatar as falas dos professores regentes das escolas, a fim de entender qual a compreensão deles acerca do papel dos estágios na aprendizagem e formação dos estagiários e futuros professores. Observemos o quadro a seguir: 
Eu acho o estágio um momento muito importante, pois é o primeiro contato formal de assumir uma sala de aula com alunos. Por que, até então, lá na universidade, os alunos têm contato com a parte teórica, mas não têm esse contato mesmo. Ele é extremamente importante [...] o estagiário vai ter contato com a escola, com os alunos, vai conhecer a realidade da profissão. É neste momento que eles vão se sentir professores de verdade. (PA escola 01)

Eu acho importante, pois o aluno que vem da universidade tem contato com a realidade da profissão e traz também coisas diferentes aos alunos da escola. Ele é extremamente significante, porque proporciona ao aluno-estagiário uma vivência do ambiente escolar. Ele acaba visualizando como é que funciona uma escola, como funciona uma sala de aula. É na escola que o estagiário fica próximo da realidade da sala de aula, compreende como é o dia a dia de um professor. (PB escola 01)

Eu vejo o estágio como um momento importante para os estagiários terem esse contato com os alunos, saber o que eles estão aprendendo, saber como nós professores regentes da escola estamos ensinando aqui na escola. Acho que tem uma troca de experiências. Foi através das experiências do estágio, vividas em sala de aula que nós, futuros professores e profissionais da área docente podemos ter contato como os saberes práticos, pois com os saberes teóricos temos mais contato na universidade. (PA escola 02)

Eu acredito que o estágio deveria começar mais no início da graduação, pois quando eles chegam aqui na escola já estão quase se formando e aí não podem aproveitar o curso com a experiência vivenciada na sala de aula e voltar à universidade para repensar e rever o que aprenderam. O estágio supervisionado é de grande importância para nossa formação como futuros professores, onde podemos aplicar os conhecimentos adquiridos na universidade na prática da sala de aula como professores. (PB escola 02)

O estágio é um momento importante onde os saberes e os fazeres da prática pedagógica são construídos no cotidiano da escola. Os professores constroem no estágio o perfil profissional que acompanhará a sua vida profissional. Recebemos muitos estagiários que não têm muita noção de como é o dia a dia na sala de aula. Muitos estão inseguros e têm receio de ficar na frente da turma. Temos de passar segurança e ficar próximos deles para ajudar no que for preciso. (PA escola 03)

Todas as disciplinas da graduação são importantes, mas o estágio é fundamental para a construção da identidade profissional. É no estágio supervisionado que ficamos frente a frente com os alunos da escola e oportuniza ao estagiário compreender como os saberes da teoria se concretizam na prática. (PB escola 03)

Para mim o estágio é um dos períodos mais importantes, pois foi através dele que pudemos adquirir experiências pessoais e na prática. O estágio não é somente uma etapa a ser cumprida e sim uma maneira de se familiarizar com o mundo da escola, dos alunos, da profissão escolhida, que é a de ser professor. (PA escola 04) 
Diante destes relatos, podemos perceber que todos os professores regentes deixam, claramente, que o estágio tem papel fundamental na formação e na construção da identidade profissional do futuro docente, possibilitando a integração entre os conhecimentos teóricos e os práticos. O estágio é um espaço que auxilia os estagiários a enfrentarem os problemas reais da sala de aula, é uma oportunidade de vivenciar a profissão, assumir a regência e experimentar as diferentes situações e os desafios da docência.

É interessante perceber que os professores destacam ser o estágio, não somente momento de prática ou de teorizar a prática, mas o de articular e inter-relacionar teoria e prática. De acordo com Piconez (1991, p. 25), o estágio é "um componente teórico-prático, isto é, possui uma dimensão ideal, teórica, subjetiva, articulada com diferentes posturas educacionais, e uma dimensão real, material, social e prática, própria do contexto da escola brasileira".

Também é destacado através dos relatos que o estágio é um momento de troca de experiências, construção de saberes e da identidade profissional. Os saberes da docência são plurais e heterogêneos, construídos e articulados no estágio, tendo papel importante na construção da identidade docente. Segundo Pimenta e Lima (2004, p. 62), o estágio é o lócus onde a identidade profissional é gerada, construída e referida; volta-se ao desenvolvimento de uma ação vivenciada, reflexiva e crítica e, por isso, deve ser planejado gradativa e sistematicamente com essa finalidade.

O estágio, nesta perspectiva, constitui-se em um processo formativo importantíssimo na construção de saberes, uma vez que se for concretizado de maneira interativa e reflexiva, contribui ao professor formador e ao futuro professor a elaboração de um processo capaz de potencializar saberes que deem sustentabilidade ao exercício da docência e novos conhecimentos na superação da dicotomia teoria e prática e o distanciamento entre a formação inicial e o cotidiano escolar. Borges (2004, p. 113) afirma que "particularmente a formação inicial deve ser encarada como uma das fontes das quais se originam os saberes dos professores".

Dando continuidade à fala com os professores, perguntamos qual a importância do professor regente da educação básica no processo de constituição da docência dos estagiários de Geografia da UDESC. De acordo com os relatos podemos observar: 
Acredito que temos um papel muito importante para os estagiários, pois os recebemos em nossas turmas e mostramos como é a realidade da prática de um professor. Podemos influenciar na escolha da carreira, pois se eles se derem bem no estágio vai influenciar positivamente na escola da profissão. Damos apoio pedagógico e emocional e ajudamos a lidar com os alunos, que é um dos maiores receios da maioria dos estagiários. (PA escola 01)

Nossa orientação é fundamental durante os estágios, pelo fato de que surgem muitas situações inesperadas, e é sempre bom ter alguma orientação para mostrar um caminho a ser seguido. No dia a dia da sala de aula, tiramos dúvidas que surgem e podemos dar conselhos sobre o que fazer diante de algum conflito ou dúvida dos alunos. Nossa experiência e prática em sala de aula ajudam no planejamento do conteúdo a ser abordado nos estágios, discutindo os problemas enfrentados no decorrer da experiência. (PB escola 01)

Auxiliamos os estagiários a enfrentar o estágio. Quando eu recebo os estagiários, procuro mostrar como trabalho com Geografia, como preparo as aulas, as provas e lido com os alunos. Há algumas turmas que são mais difíceis que outras, mas é só achar o jeito de lidar com os alunos/as. Alguns estagiários chegam à escola e sabem o conteúdo que têm de trabalhar, mas mostram dificuldade na condução das aulas, de ficar na frente da turma e se colocar no lugar do professor. (PA escola 02)

Minha responsabilidade durante os estágios é orientar no que eu puder para que os estagiários se sintam bem na escola. Procuro transmitir e trocar conhecimentos com os estagiários, preparar as aulas, criar estratégias didáticas para tornar as aulas mais interessantes aos alunos. Procuro oferecer auxílio aos estagiários no planejamento das aulas de Geografia que tenha relação com o cotidiano dos alunos, com temáticas interessantes e atuais. Preocupa-me quando os estagiários preparam aulas que não envolvem os alunos e são muito expositivas. (PB escola 02)

Tento passar segurança aos estagiários para que eles possam assumir a turma e dar suas aulas. Sei que não é fácil para quem nunca deu aula enfrentar uma turma, mas tudo tem de ter um começo. Mas para ser professor tem de desejar muito, a fim de dar conta de uma turma. Recebi estagiários que relatavam só estarem fazendo estágio por obrigação, já que não tinham outra opção. Nestes casos, fica mais complicado fazer o estágio. (PA escola 03)

Acho que nós somos um exemplo para os estagiários, por isso procuro mostrar o melhor de mim para que eles tenham um bom exemplo. Acho que meu papel é expor a realidade que eles verão na escola e na sala de aula. É no estágio que temos a oportunidade de conhecer a realidade da docência com seus pontos positivos e negativos. (PB escola 03) 
Sinto-me responsável e procuro passar uma boa impressão. Como já estamos acostumados com a turma, temos mais condições de orientar sobre as atividades que serão desenvolvidas em sala. Orientar as atividades mais viáveis para a turma, o tempo de duração, o material utilizado, os textos e os exercícios que devem selecionar. Eu acredito que, desta forma, eu ajudo os estagiários a darem uma boa aula e assim vão se sentir bem na frente da turma. Mas, às vezes, penso que não somos valorizados, considerando o papel que desenvolvemos neste processo. Pouco se fala no professor da educação básica como alguém que ajuda na formação do estagiário da licenciatura. (PA escola 04)

De acordo com as vozes dos professores regentes da educação básica, eles se sentem como orientadores e transmissores de conhecimentos, ajudando os estagiários neste período de iniciação à docência. Afirmam atuar nos estágios, orientando quando são solicitados ou quando se sentem à vontade e, em alguns casos, chegam a discutir questões relativas às aulas e até mesmo no planejamento. Entendem que são elos importantes na formação dos estagiários, mas ressaltam que não são reconhecidos dessa forma pelos outros envolvidos no processo de formação. Muitas vezes, são vistos apenas como alguém que cede a turma para o estágio e demonstra os conteúdos trabalhados na turma.

Os professores destacam que eles são vistos como um "modelo" aos estagiários, procurando ressaltar o compromisso que têm com a educação e uma postura ética diante dos alunos. Também evidenciam o apoio que procuram dar na solução de possíveis problemas surgidos no cotidiano da sala de aula, proporcionando, assim, segurança ao estagiário. De acordo com Pimenta e Lima (2004), um dos primeiros impactos dos estagiários, quando iniciam o estágio, é o susto diante da real condição das escolas e as contradições entre o escrito e o vivido, o dito nos discursos oficiais e o que realmente acontece.

Em todas as falas, seus dizeres reforçam a ideia de que são fundamentais na ajuda prestada aos estagiários com informações sobre o conteúdo e sobre o perfil da turma, na condução e controle de conflitos em sala de aula, na solução de problemas do dia a dia, na promoção da reflexão crítica acerca das situações vivenciadas e das atividades realizadas.

Como não se pode prever tudo que pode acontecer durante o estágio, é necessário lidar com o improvável e com as situações reais que acontecem no decorrer deste processo. Segundo Larrosa, a formação é 
uma viagem aberta, uma viagem que não pode ser antecipada. Portanto, é preciso "mergulhar" no mundo da prática profissional com valores, saberes e imagens adquiridas enquanto aluno e se aventurar em uma viagem por um caminho ainda pouco conhecido, uma

viagem não planejada e não traçada antecipadamente, uma viagem aberta em que pode acontecer qualquer coisa, e na qual não se sabe onde se vai chegar, nem mesmo se vai chegar a algum lugar. [...] E a experiência formativa seria, então, o que acontece numa viagem e que tem a suficiente força como para que alguém se volte para si mesmo, para que a viagem seja uma viagem interior. (1999, p. 52-53)

O sentimento de insegurança, medo e despreparo para enfrentar os desafios profissionais também é evidenciado por Huberman (1992) em seus estudos; o que ele denomina de ritual de passagem, representando a transição da vida de estudante para a de professor. Estes sentimentos geralmente estão relacionados, entre outros fatores, ao distanciamento vivenciado entre a universidade e a educação básica onde, muitas vezes, não há ligação entre as teorias vistas na graduação e o dia a dia da escola e a realidade da sala de aula.

\section{Considerações finais}

No processo de formação do futuro professor, o estágio supervisionado desempenha papel significativo, pois além de colocar o graduando em contato com o seu futuro local de trabalho, abre uma importante via de comunicação entre a universidade e a educação básica e, também, entre Geografia Acadêmica e Geografia Escolar. É um espaço de aprendizagem que não deve se constituir em mais uma atividade exigida pela legislação que compõe o currículo da licenciatura.

Através da realização desta pesquisa, buscamos compreender qual é o papel do professor regente da escola básica na formação dos estagiários e futuros docentes, destacando a importância destes profissionais e o reconhecimento do seu trabalho na formação dos estagiários. Ficou claro que a universidade deve manter projetos de parceria com as escolas da educação básica, que são lócus de estágio, pois assim é possível criar espaços com um ambiente favorável para que o estágio seja, de fato, uma experiência significativa ao futuro professor. Segundo Mizukami (2004), pesquisas colaborativas entre universidade e escola têm modificado as 
representações e as práticas nas escolas, com a aquisição de um novo discurso entre os sujeitos envolvidos com o estágio de docência, por meio de: trocas profissionais; articulação entre formação inicial e formação continuada; espaços de reflexão e mudanças nas práticas pedagógicas.

É preciso destacar que os professores da educação básica são coformadores dos estagiários que se utilizam das suas turmas na escola. Detêm papel fundamental neste processo quando disponibilizam espaço e tempo e acolhem os futuros professores que precisam pôr em prática diferentes ensinamentos e estudos sobre educação e prática da docência. Por isso é preciso um esforço no sentido de garantir aos professores, que estão dispostos a receber estagiários em suas turmas, tempo disponível na sua carga horária de trabalho para que tenham condições mínimas, efetivamente, na orientação dos futuros professores nesses primeiros contatos com a docência. É fundamental que eles tenham momentos para o planejamento das ações e das atividades dos estágios e às reuniões com os professores da universidade. Seria a institucionalização do papel do professor formador nas escolas de educação básica, atendendo aos alunos estagiários e para lhes prestar acompanhamento neste processo. Isso poderia ser feito através de convênios entre as universidades e as redes de ensino municipais, estaduais, federais e particulares.

Estendendo o escopo deste estudo, infere-se que precisamos incentivar e criar possibilidades para que a escola e a universidade tenham condições reais de trabalharem em conjunto na formação de seus professores. Criar políticas públicas que favoreçam esta articulação e deem suporte a ações que delimitem a função e o espaço de atuação dos professores regentes da educação básica na formação dos estagiários/as, sendo reconhecidos também como formadores destes futuros professores. É fundamental o engajamento e apoio para que sejam feitas mudanças estruturais nos cursos de licenciatura e nas condições de trabalho dos professores da educação básica, a fim de que seja cumprido este papel e para que possamos avançar e melhorar os cursos de formação de professores.

\section{Notas}

1. Na Universidade do Estado de Santa Catarina tem a Faculdade de Educação com 04 cursos de graduação: Geografia, História, Pedagogia e Biblioteconomia.

2. Em 2012 e 2013 foi feita uma nova reformulação curricular, separando as habilitações licenciatura e bacharelado e em 2014/1 tem início uma nova matriz curricular na modalidade Geografia Licenciatura. 
3. No momento da coleta de dados, estes professores tinham estagiários do curso de Geografia de outras universidades, mas optamos por conversar com eles por duas razões: nos anos anteriores foram acolhidos em suas turmas estagiários do curso de Geografia da FAED e por estarem envolvidos em um projeto de extensão do curso de Geografia da FAED no momento da pesquisa.

\section{Referências}

BORGES, C. M. F. O professor da educação básica e seus saberes profissionais. Araraquara: JM, 2004.

BRASIL. Lei de Diretrizes e Bases da Educação Nacional (LDB): Lei 9394/96, de 20 de dezembro de 1996.

. Parecer n. 9/2001, de 08 de maio de 2001. Diretrizes Curriculares Nacionais para a formação de professores da educação básica, em nível superior, curso de licenciatura, de graduação plena. Conselho Nacional de Educação. Disponível em: <http://portal.mec.gov.br>. Acesso em: 10 mar. 2014.

. Parecer n. CNE/CP 28/2001, aprovado em 02 de outubro de 2001. Dá nova redação ao Parecer CNE/CP 9/2001, que dispõe sobre as Diretrizes Curriculares Nacionais para a formação de professores da educação básica, em cursos de nível superior. Disponível em: <http://portal.mec.gov.br>. Acesso em: 10 mar. 2014.

. Resolução CNE/CP 01/2002, de 18 de fevereiro de 2002. Diretrizes Curriculares Nacionais para a formação de professores da educação básica, em nível superior, em cursos de licenciatura de graduação plena. Disponível em: <http://portal.mec.gov.br>. Acesso em: 10 mar. 2014.

. Resolução CNE/CP 02/2002, de 19 de fevereiro de 2002. Institui a duração e a carga horária dos cursos de licenciatura, de graduação plena, de formação de professores da educação básica em nível superior. Disponível em: < http://portal. mec.gov.br>. Acesso em: 10 mar. 2014.

HUBERMAN, M. O ciclo de vida profissional dos professores. In: NÓVOA, A. (Org.). Vidas de professores. 2. ed. Portugal: Porto Editora, 1992. p. 31-61.

LARROSA, J. Pedagogia profana. Porto Alegre: Contra \& Bando, 1999.

MARTINS, R. E. M. W. Os desafios do processo formativo do professor de geografia. Tese (Doutorado em Geografia) - Universidade Federal do Rio Grande do Sul, Porto Alegre, 2010.

MIZUKAMI, M. da G. N. Aprendizagem da docência: algumas contribuições de L. S. Shulman. Revista Educação, v. 29, n. 2, 2004. Disponível em: <http://www. ufsm.br/ce/revista/revce/2004/02/a3.htm>. Acesso em: 10 mar. 2014.

PICONEZ, S. C. B. A prática de ensino e o estágio supervisionado: a aproximação da realidade escolar e a prática da reflexão. In: PICONEZ, S. C. B. (Org.). A prática de ensino e o estágio supervisionado. Campinas: Papirus, 1991. p.15-38.

PIMENTA, S. G.; LIMA, M. S. L. Estágio e docência. São Paulo: Cortez, 2004. 
UNIVERSIDADE DO ESTADO DE SANTA CATARINA. Projeto Político Pedagógico do Curso de Geografia. Florianópolis, 2008. Disponível em: <http://www.faed. udesc.br/arquivos/id_submenu/510/pppgeografia.pdf>. Acesso em: 10 mar. 2014.

Rosa Elisabete Militz Wypyczynski Martins - Possui Licenciatura Plena em Geografia pela Universidade Regional do Noroeste do Estado do Rio Grande do Sul. Mestrado em Educação pela Universidade de Passo Fundo e Doutorado em Geografia pela Universidade Federal do Rio Grande do Sul. Atualmente é professora na Universidade do Estado de Santa Catarina.

Recebido para publicação em 19 de abril de 2015

Aceito para publicação em $1^{\circ}$ de junho de 2015 